\title{
Cognition and construction of the theoretical connotations of new urbanization with Chinese characteristics
}

\author{
CHEN Mingxing ${ }^{1,2}$, YE Chao ${ }^{3}$, LU Dadao ${ }^{1,2}$, SUI Yuwen ${ }^{1,2},{ }^{*}$ GUO Shasha $^{1,2}$
}

1. Key Laboratory of Regional Sustainable Development Modeling, Institute of Geographic Sciences and Natural Resources Research, CAS, Beijing 100101, China;

2. University of Chinese Academy of Sciences, College of Resource and Environment, Beijing 100049, China;

3. College of Geographic Sciences, Nanjing Normal University, Shanghai 200241, China

\begin{abstract}
Since the reform and opening up in China, rapid urbanization has boosted the development of economy and society, but it has also been confronted by tremendous challenges. Multidisciplinary research has focused on the issue of a national new type of urbanization planning, leading to a transformation of China's urbanization strategy. Further research, however, is needed to explore the theoretical basis for this new approach to urbanization. This paper summarizes the process of development of urbanization in China and describes its specific characteristics, including peri-urbanization, special national conditions, complicated factors, and governance system. China's urbanization makes a great contribution to urbanization on a world scale. Moreover, the literature on the subject demonstrates the significance of urbanization to the discipline of human and economic geography and the scientific connotations of new urbanization, which is people-oriented, harmonious, inclusive, and sustainable. Against a background of humanism, new urbanization represents a transformation from population urbanization to people-oriented urbanization. There are six crucial scientific issues involved: people-oriented urbanization and equalization of basic public services; urbanization with integrated and coordinated urban and rural development; urbanization in the context of resources and environmental carrying capacity and climate change; diverse regional modes; spatial effect and mechanism; and big data and technical innovation. The paper aims to illustrate the theoretical framework of China's new urbanization, providing references for both theoretical research and policy formulation.
\end{abstract}

Keywords: new urbanization; Chinese characteristics; theoretical connotations; people-oriented urbanization; sustainable urbanization

\section{Introduction}

Urbanization is an inevitable trend in economic and social development. Since the reform

Received: 2018-12-18 Accepted: 2019-03-01

Foundation: National Natural Science Foundation of China, No.41822104, No.41842058, No.41671125

Author: Chen Mingxing (1982-), PhD and Professor, specialized in urbanization and regional sustainable development. E-mail: chenmx@igsnrr.ac.cn

*Corresponding author: Guo Shasha (1994-), E-mail: guoss.17s@igsnrr.ac.cn 
and opening-up in China, rapid urbanization has led to great economic and social development, with improvements in the lives of both the urban and rural populations. In the 1990s, the dominant view was that China needed to conform to the worldwide trend and implement a strategy of accelerating urbanization, and indeed China's urbanization rate rose from $30 \%$ to $36 \%$ during the period from 1996 to 2000 . It was partly on the basis of this strategy that local governments pursued policies of rapid urbanization. In both government reports and the research literature, the rapid growth in the urbanization rate is regarded as an important achievement. However, continuous high-speed urbanization has gradually come to be considered as a rash choice (Lu and Yao, 2007; Lu et al., 2007), with the continued expansion of urban agglomerations coming into conflict with the constraints imposed by limited resources (Fan et al., 2013).

Scholars in the fields of human and economic geography, resources and environmental science, and urban regional science have conducted in-depth research on the cognition of urbanization laws (Xue and Zhen, 2001; Zhou, 2006; Gu and Wu, 2008; Fang and Wang, 2011; Yao et al., 2011; Chen, 2012; Chen et al., 2013; Jin, 2013; Chen et al., 2014b; Li and Luo, 2014), the problems in urbanization of different types of districts (Zhang, 2004; Chai et al., 2011; Luo et al., 2012; Fan et al., 2013b; Zhang and Du, 2013; Fang, 2014), the urbanization patterns in different regions (Liu and Yang, 2012; Chen et al., 2013b; 2014a; Gao et al., 2014), and the dynamic mechanism of urbanization (Ning, 1998; Chen et al., 2009; Liu and Li, 2009; Chen, 2012; Wei et al., 2013; Zhou and Ye, 2013a; Liu and Jin, 2014; Chen et al., 2015). These studies have had an important influence on the production of the National New Urbanization Plan (2014-2020) (NNUP). This plan represents a major adjustment in the direction of development of urbanization in China. The view that the accelerated urbanization elsewhere in the word should lead to implementation of a similar strategy in China has gradually disappeared from government documents and reports. The general consensus has become that there should be a greater focus on the quality of urbanization, and the development goal has become a new type of people-oriented urbanization. Even some of those experts who still insist that China's urbanization level is lagging now hold the view that this is due to the slow pace of peasants' integration into urban life rather than to a low rate of urbanization of the population. This kind of lagging urbanization is essentially not contradictory, and indeed is even consistent with our view.

The new urbanization strategy is based on a review and adjustment of the previous approach, and also forms a starting point for research into the practical application of urbanization in China. However, how to further promote healthy and sustainable urbanization remains an important academic issue. Human and economic geography is obviously interdisciplinary in nature, constituting a discipline that deals with real-world issues and plays an important role in national strategic decision-making and social practice (Liu, 2014). Geographers' knowledge structure also plays an important role in studies of urbanization (Lu, 2013). At the same time, human and economic geography is also influenced by Western centralism. On the one hand, since the advent of reform and opening up, the concepts, theories, and paradigms of urbanization introduced in the Chinese academic community have mostly come from the West, and are mainly based on Western urbanization and its experience with economic and social development. On the other hand, there is a barrier to publication in world-class journals and thus to accessibility imposed by the constraint that only those who conform to mainstream views and the theoretical paradigm of Western human and economic 
geography can be recognized as "orthodox" (He and Huang, 2017). The limitations of this direct borrowing of Western urbanization theories and paradigms have also become increasingly evident. The evolutionary mechanism of urbanization with Chinese characteristics is much more complicated than that of urbanization in developed countries and regions. The Western model is not completely suitable and is even inconsistent with the reality of China's urbanization and urban development (Zhou and Ye, 2013b). Starting from China's national conditions and practical issues, it is very important to introduce Western theories with a critical eye, strengthen theoretical self-confidence and self-awareness, and promote urbanization research on the basis of scientific norms, interdisciplinary intersections, and the introduction of new methods (Miao, 1999; He et al., 2014; Li et al., 2014; Xue and Wang, 2014).

The practice of China's new approach to urbanization has also provided valuable research materials and opportunities. The most urgent problem to be solved is how to understand new urbanization in a scientific manner. Obviously, "new" here is not simply a contrast to "old", but has to be seen in the context of what was done in the past. What exactly is different from the past? What are the theoretical connotations of the new urbanization? On the basis of a summary of the uniqueness of China's urbanization, this paper describes its contributions and its significance, analyzes its theoretical connotations, and proposes important topics that need to be focused on in the future. The aim is to present a scientific understanding of new urbanization with Chinese characteristics and thus provide ideas for reference concerning the successful implementation of the NNUP.

\section{The uniqueness, world contribution, and academic significance of ur- banization with Chinese characteristics}

\subsection{The uniqueness of urbanization with Chinese characteristics}

(1) The giant scroll of urbanization with Chinese characteristics. China's urbanization process is surging forward with great momentum, and China has experienced the greatest transformations of farmers to citizens and of rural to urban areas in human history. The speed and scale of these transformations is striking. Looking back on the urbanization process over the past 30 years, the number of cities has increased constantly. The scale of cities has been expanding, and the urbanization rate has risen rapidly from $24.52 \%$ in 1986 to $57.35 \%$ in 2016 , with an average annual growth rate of 1.1 percentage points. The urban population has rapidly tripled from 260 million to 790 million: a net increase of 530 million. At the same time, the rural population has dropped by 220 million from 810 million to 590 million. In addition, the area of construction land has grown rapidly from $10,161 \mathrm{~km}^{2}$ in 1986 to $52,761 \mathrm{~km}^{2}$ in 2016 , an increase by a factor of 5.2. From these facts, we can see that the speed and scale of China's urbanization are unprecedented. At the 19th CPC National Congress in 2017, in a review of the brilliant achievements since the 18th Congress, it was pointed out that the urbanization rate had increased by an average of $1.2 \%$ per year and that more than 80 million people from agricultural communities had been transformed into urban residents.

(2) Migrant workers like migratory birds and semi-urbanization characteristics. The characteristics of semi-urbanization are mainly reflected in their social and spatial aspects. From the social point of view, groups of migrant workers have spread out like migratory birds, which has led to a number of problems, such as the women, elderly, and children left 
behind in the countryside, a problem that is exacerbated yearly by the Chinese Spring Festival travel rush. The number of migrant workers in China continues to grow. In 2016, the total number of migrant workers reached 281.71 million, an increase of 4.24 million over the previous year. Of these, 112.37 million were classed as "local workers." Migrant workers were regarded as resident populations of towns. However, in reality, the living standards of most of this group did not achieve urban levels, nor did they generally become involved in urban society. From a spatial perspective, there is a specific semi-urbanized landscape where "villages are like towns while towns are like villages" (Liu et al., 2004). In addition, the urban-rural gap has widened in the process of urbanization, with rural areas facing the risk of becoming vacant.

(3) The particularity of China's basic national conditions and the limited livable space. There are huge variations in natural conditions among the different regions of China. Generally speaking, there are three levels of terrain in China. The Qinghai-Tibet Plateau is the highest level, with an average elevation of more than 4000 meters, a cold climate, and low population density. To the east of Daxinganling (Da Hinggan Mountains), Taihang Mountain, and Funiu Mountain there is generally the lowest terrain in China, mostly plains and hills below 500 meters. It mainly comprises the eastern coastal areas, the northeastern regions, and the central regions, with good hydrothermal conditions. The intermediate level of terrain includes plateaus and basins with altitude ranging mostly from 2000 to 1000 meters. Correspondingly, three major natural areas have formed: the eastern monsoon climate zone, the northwest arid and semi-arid zone, and the Qinghai-Tibet alpine zone. The three major levels of terrain and the three major natural areas determine the macroscopic framework and basic structure in which China's urbanization and the corresponding economic and social activities proceed. It should be noted that there are many mountainous areas in China and relatively little flat land. About $60 \%$ of the land area comprises mountains and plateaus, and therefore the livable land area is limited.

(4) Synchronous interweaving of factors of influence and the complexity of the system. China has specific national cultural and historical traditions, which have been formed at specific times and against specific institutional backgrounds. Consequently, it has experienced complex processes of urbanization and economic growth, influenced by a range of intertwined factors. Over the years, various new factors have emerged, such as economic globalization, innovations in technology (including the information technology revolution), great improvements in transportation, and the rapid development of service industries. To advance, urbanization needs to proceed alongside and in cooperation with industrialization, developments in information technology, agricultural modernization, and greening.

(5) Unique governance system and institutional mechanisms. An important feature of China's urbanization is the government-led urbanization model. By formulating laws, regulations, public policies, and other means, this promotes, guides, and regulates the urbanization process and plays a fundamental and leading role in rural-to-urban population migration, urban agglomeration, internal structural adjustments and external expansion of urban areas, competition and coordination between cities, and regulation of urban-rural relations. The government plays at least four roles in the process of urbanization, including the formulation of urbanization strategies, the supply of urbanization systems, the implementation of new urban construction, and the evaluation of urbanization performance. A series of urbanization-related governance policies, represented by the household registration system, land 
ownership, and the government's monopoly on the land development market, have indeed played an important role in certain stages. However, at present, the formulation of such policies must take account of different degrees of change, innovation, and the need for improvements to adapt to new developments in urbanization.

\subsection{The great contribution of China's urbanization to the world}

Between 1986 and 2016, the world urbanization rate rose from $41.5 \%$ to $54.3 \%$, an increase of 12.8 percentage points in 30 years. At the same time, China's urbanization rate rose rapidly from $24.52 \%$ to $57.35 \%$, changing from a level far below the world average to surpass it. These figures have been obtained using the method of calculating the contribution rate given by Cao and Liu (2011), according to which the change in the world urbanization rate during the study period is given by

$$
\Delta U=U^{*}-U=\frac{C^{*}}{P^{*}}-\frac{C}{P}=\frac{\sum_{i} U_{i}^{*} P_{i}^{*}}{P^{*}}-\frac{\sum_{i} U_{i} P_{i}}{P}=\sum_{i}\left(\frac{U_{i}^{*} P_{i}^{*}}{P^{*}}-\frac{U_{i} P_{i}}{P}\right)
$$

where the world urbanization rates at the beginning and end of the study period are respectively denoted by $U$ and $U^{*}$, the corresponding urban populations by $C$ and $C^{*}$, and the corresponding total populations by $P$ and $P^{*}$. The index $i$ labels the countries involved in this study. The contribution of country $i$ to the increase in the world urbanization rate during the study period is given by

$$
G_{i}=\frac{U_{i}^{*} P_{i}^{*}}{P^{*}}-\frac{U_{i} P_{i}}{P}
$$

with the corresponding contribution rate being given by

$$
R_{i}=\frac{G_{i}}{\Delta U}
$$

From 1986 to 2016, China has made the greatest contribution to the world urbanization rate, namely, $42.32 \%$. In the same period, the remaining nine of the top ten countries with the most urban population in the world were India, Brazil, Indonesia, Mexico, Nigeria, Pakistan, the United States, Japan, and Russia, with contribution rates of $14.91 \%, 3.21 \%$, $7.73 \%, 1.95 \%, 5.89 \%, 3.49 \%,-0.67 \%,-2.27 \%$ and $-5.38 \%$, respectively. The contribution rate from other countries as a whole is $28.77 \%$, which is far below that of China. If we consider this issue in different periods, then, from 1986 to 2000, China's contribution rate increased from $40.51 \%$ to $47.9 \%$; from 2000 to 2005 , it showed a slow downward trend; and from 2005 to 2016, it showed a significant downward trend, from $45.26 \%$ to $35.81 \%$, but still maintained a high rate of more than $35 \%$ (Figure 1). In addition, the world's urban population nearly doubled from 2.036 billion in 1986 to 4.027 billion in 2016. The Asian urban population increased from 876 million in 1986 to 2.132 billion in 2016 . From 1986 to 2016, China's urban population increased by 531 million, accounting for more than a quarter $(26.69 \%)$ of the world's new urban population, and not far off a half $(42.29 \%)$ of the new urban population in Asia.

Thus, China's urbanization has undoubtedly been an important part of world urbanization, and indeed the main driving force in the past 30 years. The development of urbanization has also promoted the growth and recovery of the world economy. In the future, China will still 


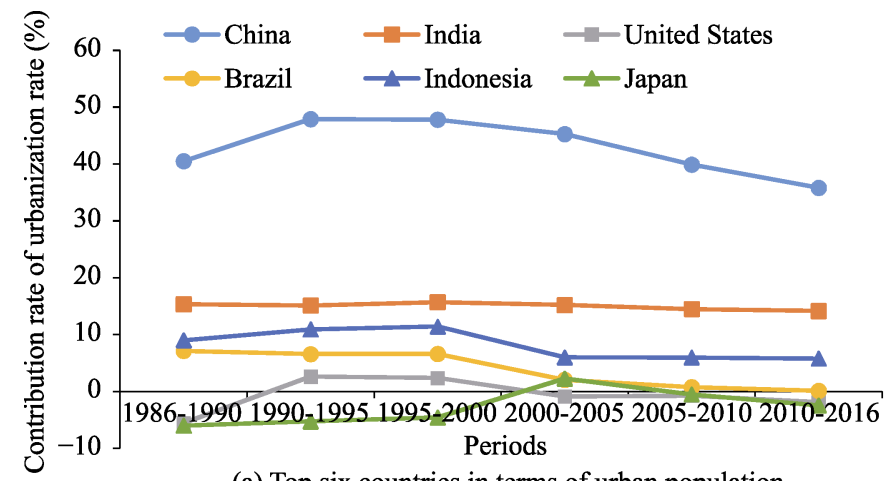

(a) Top six countries in terms of urban population

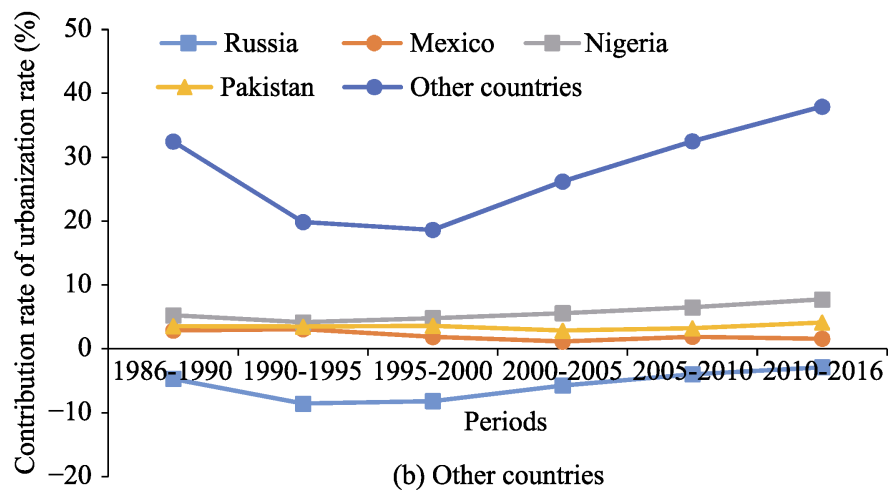

Figure 1 Contributions of different countries to global urbanization from 1986 to 2016

have hundreds of millions of the agricultural population moving to cities. This will have a positive and far-reaching impact on China and on the world as well. China's urbanization is generating tremendous opportunities for development, but also, of course, is faced with the challenges of sustainable development. From a global perspective, China's urbanization is in an intermediate stage of development. On the one hand, urbanization in developed regions such as Europe and the United States has entered a mature stage, with rich accumulated experience in the associated approaches, models, and technologies. China must actively learn from this experience, which can provide inspiration for China's new urbanization. On the other hand, China's urbanization level is higher than that of some underdeveloped countries. With regard to the aspects of urbanization development, poverty alleviation, employment promotion, infrastructure improvement, and economic growth, the history and experience of China's urbanization has provided a good model and example for underdeveloped countries and regions around the world. Of course, the difficulties and challenges faced by China's high-speed urbanization can also provide a reference to allow these countries and regions to avoid some detours and pitfalls. Thus, global cooperation with regard to urbanization has good prospects, and China plays an important role in this process.

\subsection{Disciplinary significance}

Urbanization research is interdisciplinary in nature. In recent years, the number of research papers on urbanization in the SCI/SSCI literature library and the CNKI core journal literature database have generally increased at a rapid rate (Figure 2a). Among these, the number 
of urbanization papers included in SCI/SSCI has increased considerably since 1995, reaching 480 in 2017; the number of urbanization papers included in the CNKI library has also increased significantly since 2000 , reaching a peak of 2741 in 2014 . However, since then, an

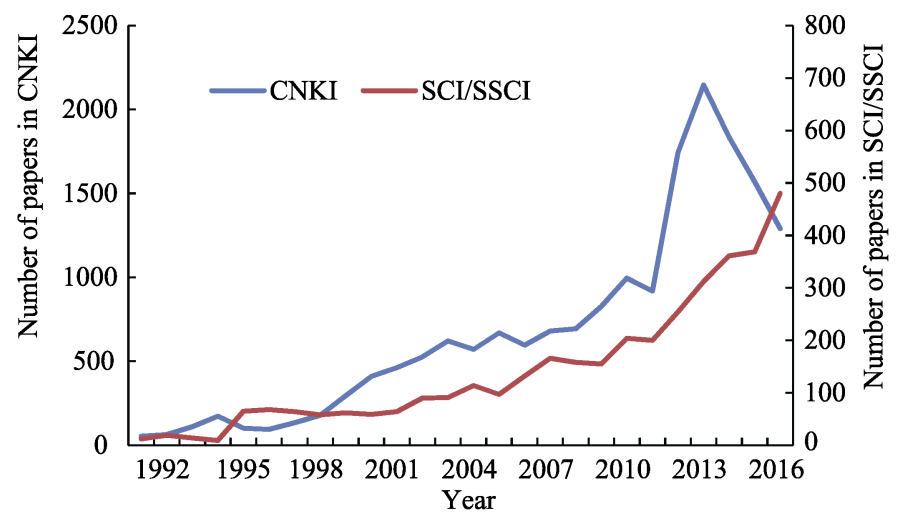

(a) Changes in number of papers

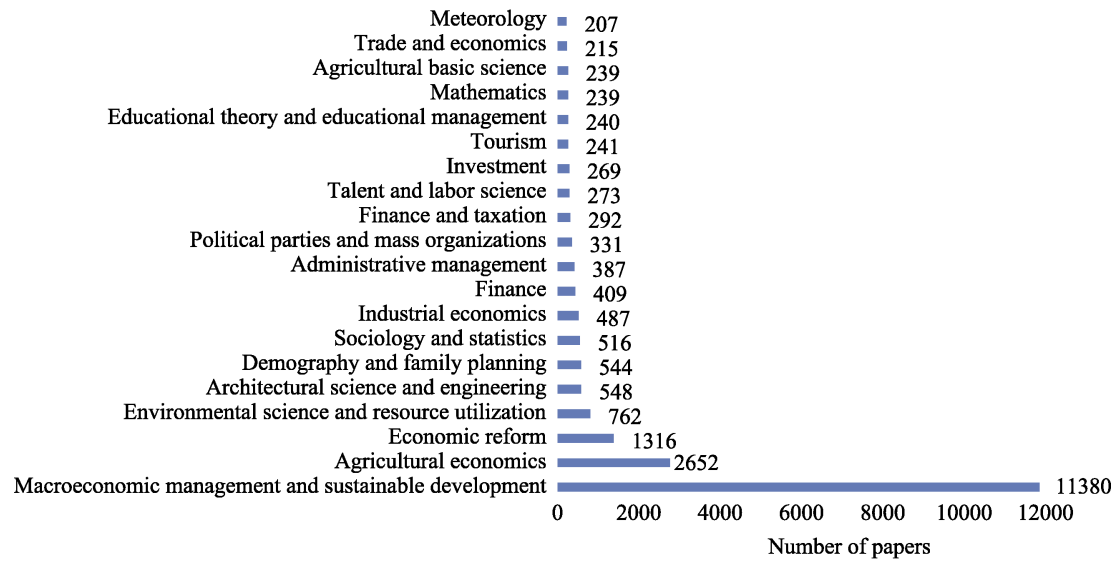

(b) Categories of papers in CNKI

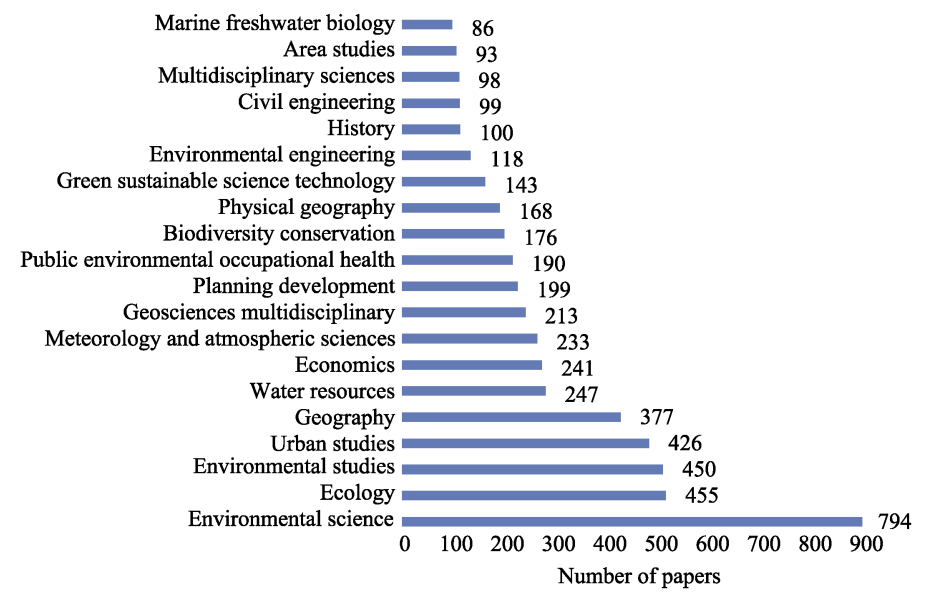

(c) Categories of papers in SCI/SSCI

Figure 2 Statistical analysis of literature on urbanization from 1992 to 2017 
interesting phenomenon has appeared: since the release of the NNUP, the number of relevant studies in the CNKI library has dropped significantly. The main reason for this may be that urbanization research in China has entered a new phase, with the difficulty and depth of this research both increasing. From the perspective of disciplinary distribution, CNKI's papers on urbanization are mainly concentrated in macroeconomic management and sustainable development, agricultural economics, economic reform, environmental science and resource utilization, architecture, demography, sociology, and industrial economics (Figure 2b). The urbanization-related papers included in SCI/SSCI mainly cover the fields of environmental sciences, ecology, urban studies, geography, resources, economics, meteorology, geosciences, planning development, and public environment (Figure 2c). This highlights the important academic significance and value of urbanization as a topic of great current significance, with aspects involving multiple disciplines: geography, planning, resources science, economics, demography, urban studies, and geosciences.

From the perspective of geography, especially human and economic geography, the academic significance of urbanization issues is particularly prominent. Geography focuses on the interaction and feedback between human and nature on the epigeosphere (Wu, 1991). Rapid economic and social development has greatly changed China's natural structure and its socio-economic structure, with environmental changes now being governed predominantly by human activities rather than by natural phenomena (Lu and Cai, 2001). Urbanization is a major aspect of both national and regional development ( $\mathrm{Lu}, 2013)$. It is an integrated geographical process dominated by the most important human activities on the surface of the Earth. The mechanism of interaction between humans and nature is complex. In this context, it is important to bring in Western theories in a critical manner, strengthen theoretical concepts and innovations, seek theoretical breakthroughs, and promote and develop quantitative modeling methods (Liu et al., 2014; Zhen et al., 2015; Gu et al., 2017). Owing to the unique way in which urbanization has proceeded in China and its great contribution to urbanization on a worldwide scale, extremely rich and fertile soil has been provided for urbanization research in China. To summarize the experience and lessons of urbanization in a timely manner, there is an urgent need for multidisciplinary collaboration in China to gradually establish independent theoretical methods and cultural self-confidence in new urbanization with Chinese characteristics, with the aim of founding an internationally influential and multidisciplinary subject area and catching up with and indeed playing a leading role in the international academic community.

\section{The connotations of new urbanization theory}

The theoretical connotations of new urbanization include at least four aspects, namely, humanism, harmonism, inclusiveness, and sustainability, and it involves a transformation from "urbanization of population" to "urbanization of people," with a corresponding transformation from structuralism to humanism.

\subsection{Humanism}

The new urbanization reflects the transformation of the value concept of urbanization from structuralism to humanism. Structuralism emphasizes the state of determining and being determined that exists in interconnected elements of things. Although post-structuralism has 
inherited the link of structuralism to the relationship of things, it rejects the concepts of decision, domination, and a solidified and grand structure, and instead bases itself on the idea of diverse and evolving processes (Cresswell, 2013). Humanism explores the development of human beings, individually and collectively. Humanistic geography thus has two fundamental aspects: at the individual level, it emphasizes the spatial relationships among values, personality, feelings, psychology, and geography; at the cultural level, it emphasizes he relationships among history, philosophy, social and organizational behavior, economics, political groupings, and geography (Tuan, 1976; Ye et al., 2014). Of the two contemporary academic schools in Western geography, structural geography pays more attention to social structural dynamics, while humanistic geography arises from the understanding of individual emotions and values and their relationship to spatial senses on different scales (Zhou et al., 2011). In this context, the development of urbanization should reflect the three vital benefits of a people-oriented approach, namely, identity, security, and incentives (Porteous, 1976). This humanistic concept permeates all relevant events. Structuralism and humanism, if taken as mutually complementary approaches, allow for the development of more open and inclusive ideas and thereby an ideological renewal. These ideas have also profoundly enriched the theoretical connotations of urbanization. In particular, the ideas of multi-scale "deconstruction-reconstruction" and "people-orientation" have laid a solid ideological foundation for the transformation of "population urbanization" to "people-oriented urbanization."

\subsection{Harmonism}

Urbanization is a process of transformation from a traditional agricultural society to a modern urban society, involving many elements, such as population concentration in urban areas, and therefore there is a corresponding economic transformation to a non-agricultural economy as well as a transformation of the landscape. Urbanization is a multidimensional complex process in social space (Friedmann, 2006). Owing to the comprehensive nature of urbanization, its multidimensional elements, such as population, land, economy, and society, must be coordinated. Studies have shown that in the process of rapid urbanization in China, the main feature is the rapid evolution of economic growth and regional landscape, followed by population urbanization, and finally changes in healthcare in social urbanization. The subsystems involved in urbanization, such as population, economy, society, and land, also have different characteristics at different stages (Chen et al., 2009). The NNUP issued by China in 2014 clearly points out the prominent contradictions that have arisen in rapid urbanization in the past. Among these, the first is the difficulty faced by a large number of agricultural migrant workers in integrating into urban society, such that the process of "citizenization" lags behind. The second is that "land urbanization" is faster than "population urbanization" and that the utilization of construction land is inefficient. The problems reflected in these two contradictions are ultimately based on the lack of coordination among multiple factors in the process of urbanization, with some factors developing too rapidly and others too slowly. The first contradiction is due mainly to a lack of urbanization of social factors, and the second arises mainly because the evolution of the land factor is faster than that of the population factor. Both lead to further contradictions in the complex system of urbanization and hinder the healthy development of urbanization. Therefore, the speeds of evolution of the multidimensional elements of urbanization should match each other to promote effective realization of new urbanization. Through a quantitative assessment of the 
evolutionary process and degree of synergy of population, land, and economy in the process of urbanization, the parameters associated with the evolution and its threshold range can be analyzed in depth according to the different stages of the urbanization process. Synergy should also be reflected in the spatial pattern, that is, in the realization of spatial equity and spatial justice (Soja, 2009). That is to say, in the process of spatial agglomeration and parting, the urbanizations of population, of economy and land, and of social factors should match one another. Against the background of new urbanization, it is necessary to comprehensively consider the degree of actual acceptance of population in each region, and take people-oriented urbanization as the core, equipped with the corresponding construction land indicators, in order to promote the orderly flow and coordinated development of various elements of urbanization in space.

\subsection{Inclusiveness}

In 2007, the Asian Development Bank (ADB) released a report entitled Defining and Measuring Inclusive Growth: Application to the Philippines, which proposed and defined the concept of "inclusive growth," with the aim that the opportunity to ensure economic growth should be shared by everyone and made available to all, particularly the poor (Ali and Son, 2007). Inclusiveness emphasizes a more equitable development philosophy that is important for new urbanization. The inclusive content of new urbanization is mainly reflected in the three aspects of urban and rural area, floating population, and vulnerable groups. First, urbanization itself is a development issue at national and regional scales, not just urban development. It is of no practical significance to analyze the level of urbanization in urban built-up areas. It is the relationship between urban and rural areas, whether they will be isolated or interactive, that is of major impact on the long-term development of urbanization. In general, in the past, considerations of the urbanization process paid more attention to the cities, while rural development was relatively neglected. The absolute income gap between urban and rural areas continues to widen, and villages have even experienced the crisis of vacancy. The new urbanization and rural revitalization strategies are closely integrated to promote urban and rural development. Second, considering the problem of a growing urban floating population, the new generation of migrant workers generally faces the dilemma of being both unable to enter the city and unable to return to their villages.

On the one hand, there have been rapid increases in the cost of public services. For example, the low income level of most migrant workers means that they have increasing difficulty in buying houses in the cities and have no alternative but to share rented rooms with other migrant workers. On November 18, 2017, there was a disastrous fire in the Jufuyuan Apartments in Xihongmen Town, Daxing District, Beijing City, involving the loss of 19 lives. In fact, Jufuyuan Apartments is a typical industrial complex, integrating storage, manufacturing, and residential functions. The basement is a cold storage warehouse, the first floor is a commercial workshop, and the second and third floor are residential, with extremely high security risks. On the other hand, the new generation of migrant workers have become accustomed to life in the cities and most are not familiar with rural labor and are unwilling to return to the countryside. This is a prominent contradiction that has emerged during the rapid development of urbanization and is also a focus of new urbanization. Third, with regard to vulnerable groups, these include the women, elderly, and children left behind in rural areas. They suffer from a lack of daily family affection and of satisfactory material living condi- 
tions. Vulnerable groups also include the urban poor. As the price of urban housing rises, there is a hierarchical differentiation among urban residents: between the old citizens and the new citizens, as well as the between different income groups in different industries. This differentiation has led to the emergence of new urban binary structures. In this context, new inequities and spatial zoning in urban geospatial spaces have attracted widespread attention.

\subsection{Sustainability}

In the past, urbanization gave little consideration to the carrying capacity of resources and environment. Urbanization in all regions of China has occurred with great speed. This mode of extensive urbanization has had serious negative effects on resources and environment, and in turn these negative effects have had a feedback effect on the speed and quality of urbanization. As China's urbanization rate has approached $60 \%$, it has also gradually entered the mid-late stage of development where improving quality is one of the main goals. Moreover, "socialism with Chinese characteristics" has entered a new era, and the main contradictions in Chinese society have been transformed into contradictions between people's growing needs for a better life and the development of unacceptable imbalances. A good life requires not only satisfactory material living conditions, but also a high-quality and livable environment, including clean air, clean water, safe and pollution-free cultivated land, beautiful natural landscapes, and a reasonable carbon emission scale.

The new urbanization gives full consideration to consistency with conservation of water and land resources and environmental carrying capacity, in a fundamental change from the previous urbanization model, which did not pay any attention to the natural geographical environment. Depending on the carrying capacity of resources and environment in different regions, the number, scale, and spatial agglomeration patterns and distribution of cities within each region are reasonably determined so as to further optimize the spatial pattern of the land, to strengthen the scientific evaluation of urbanization and resource security and the support capacity of the environment (including ecological carrying capacity), and to provide key assurances for new urbanization through scientific monitoring, dynamic assessment, and a guarantee of timely warning. In addition, the development and adaptation of urbanization in the context of climate change is an indispensable part of new urbanization. The fifth climate change assessment report by the United Nations Intergovernmental Panel on Climate Change (IPCC), Working Group I Report: Climate Change 2013: The Physical Science Basis, reported that the evidence for global warming and its close relation to human activities is now more conclusive (Stocker et al., 2014). Working Group II Report: Climate Change 2014: Impacts, Adaptation, and Vulnerability focused on the impacts of climate change and adaptation vulnerabilities, recognizing that human systems exhibit significant vulnerability and have been exposed to climate change risks, in particular to extreme climates (Field et al., 2014). Working Group III Report: Climate Change 2014: Mitigation of Climate Change pointed out that emissions by human activities have significantly grown, causing global and regional climate changes, and that emission reduction policy measures should be adopted to mitigate climate change and promote sustainable development (IPCC, 2014). The global urbanization process has led to significant changes in the surface structure of the Earth, especially in key urban agglomerations and metropolitan areas. For example, the nighttime light index intensity in China increased significantly between 1992 and 2013 (Figure 3). Urbanization has also increased energy use and greenhouse gas emissions. Therefore, sus- 
tainability is an important connotation of new urbanization, taking account, at the very least, of resource-saving and environmentally friendly measures, preservation of biodiversity, and the need for climate adaptation.
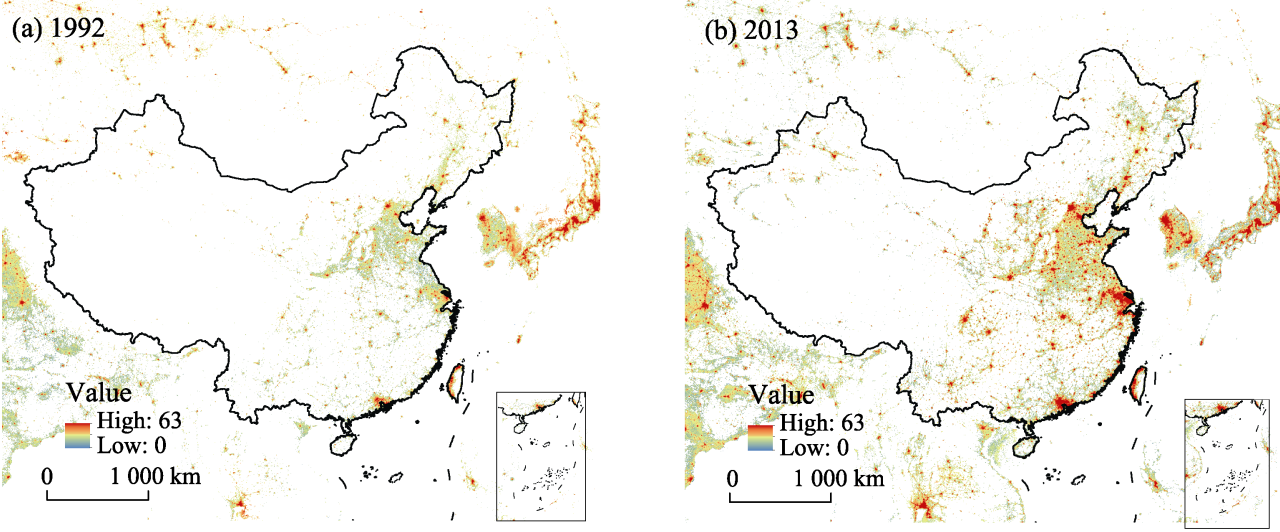

Figure 3 Comparison of China's nighttime light index intensity from 1992 to 2013

\section{Key issues in the study of new urbanization}

Focusing on the four main aspects of new urbanization theory, this paper proposes six key research topics in view of the prominent contradictions and new problems facing current urbanization development: basic public services; urban and rural integrated processes and synergy; resource environment and climate changes; diversified regional models; spatial production mechanisms; and technical innovations, all of which are closely related to the connotations of new urbanization theory. These issues are related and compounded in four aspects, but different topics have different focuses and connotations (Table 1).

Table 1 Correlations between the key issues and theoretical connotations of new urbanization

\begin{tabular}{lcccccc}
\hline & $\begin{array}{c}\text { Public } \\
\text { services }\end{array}$ & $\begin{array}{c}\text { Integrated } \\
\text { processes }\end{array}$ & $\begin{array}{c}\text { Resource } \\
\text { environment }\end{array}$ & $\begin{array}{c}\text { Regional } \\
\text { models }\end{array}$ & $\begin{array}{c}\text { Spatial } \\
\text { production }\end{array}$ & $\begin{array}{c}\text { Technical } \\
\text { methods }\end{array}$ \\
\hline Humanism & +++ & ++ & ++ & + & ++ & ++ \\
Synergy & ++ & +++ & ++ & +++ & + & ++ \\
Inclusiveness & +++ & + & + & +++ & ++ & ++ \\
Sustainability & + & +++ & ++ & + & ++ \\
\hline
\end{tabular}

+++ , strong correlation; ++ , medium correlation; + , weak correlation.

\subsection{Urbanization of human and equalization of basic public services}

Efforts should be made to construct a new urbanization development theory and model that is compatible with China's economic and social development level and can accommodate people's living and production needs, promote sustainable and harmonious economic and social development, and conform to China's national conditions. To facilitate urbanization of people, there should be in-depth analyses of the size, characteristics, distribution pattern, and migration mechanisms of migrant groups. The citizenization of migrant workers satisfying certain conditions should be actively promoted, so that they can live and work in peace and contentment at all levels in the cities. Openness and inclusiveness in the eastern urban re- 
gions should be improved, allowing migrant workers and vulnerable urban groups to share basic public services such as healthcare, education, security, culture, and sports, and gradually leading to equalization of basic public services in large, medium, and small cities. At the same time, through integration with the rural revitalization strategy, there should be equalization of basic public services in urban and rural areas, and new urbanization should be promoted in urban and rural areas. In addition, attention should be paid to the housing problem - one of the key difficulties in urbanization - and there should be an in-depth study of the total housing volume, residential structure, occupational and housing balance, housing destocking, etc., and their relationship with the presence of migrant workers. The aim should be to restore housing to its main purpose — of providing living accommodation.

\subsection{Urban and rural integration and coordination of the elements of urbanization}

The study of processes is the focus of geographic research and one of the important ways in which it has established itself as a scientific discipline. Urbanization is the most significant process in human and economic geography. Therefore, it is necessary to strengthen integration of research into urbanization and provide a deeper understanding of the scientific issues involved, such as the motivation, stage, evolution, and trend of this process. This requires analyses of the urban-rural evolution of population, economy, land, and society in the process of urbanization. In addition, a comprehensive framework should be established for the analysis of population agglomeration, economic growth and non-agricultural employment, and non-agricultural utilization of land, in order to determine the transformation processes and patterns involved. From such analyses, the synergistic parameters and thresholds of evolution of multiple factors in the process of urbanization can be identified and a synergistic evolution model of each factor established. On this basis, the characteristics and laws of urban and rural spatial evolution of urbanization can be explored. The changes in dynamical mechanisms in the mid-late period of urbanization should be studied. For example, technological innovation is important for promoting the transformation from the old to the new model of urbanization. In addition, the new industries supporting the development of urbanization, such as modern service industries, emerging strategic industries; tourism+; intelligent manufacturing; integrated primary, secondary, and tertiary industries; and information and e-commerce, are also the research directions worthy of attention.

\subsection{Resources and environmental carrying capacity and climate adaptation}

New urbanization must give full consideration to new issues such as resources and environmental carrying capacity (Fu et al., 2015) and their adaptation to climate change (Zhu et al., 2017). For example, with regard to the relationship between urbanization and atmospheric pollution, it is important to consider how the "blue sky protection campaign" should be conducted. A monitoring and pre-warning mechanism for resources and the environmental carrying capacity of urbanization development should be established, the relationships between resources and environment and urbanization should be explored, and basic indicators for regional full-coverage evaluation should be selected. The key thresholds of various special indicators for different types of regions need to be identified and then classified and evaluated. Finally, overload warnings should be established based on thresholds such as a reasonable scale of population and urbanization development under the constraints of re- 
sources and environment, key constraint indicators should be identified, and a response path should be proposed. In addition, as the impact of climate change continues to increase and the urban population density grows, so too does the density of buildings, leading to vulnerabilities to the adverse effects of climate change. The task of adapting urbanization to climate change is very arduous, and the dual objectives of rational urbanization and climate protection must be considered. The mode of urbanization development needs to adapt to the changing climate and the exploration of new urbanization needs to be strengthened, with account taken of green issues such as the requirement for reduced carbon emissions.

\subsection{Diversified regional models and typical regions}

China covers a large land area, and there are significant regional differences in natural background, economic and social foundations, historical cultures, and national customs. New urbanization should explore diversified regional models in different regions. Already, there have been successive announcements of three batches of new urbanization pilot areas, bottom-up experience has been summarized, and independent and objective third-party evaluations have been conducted, consolidating regional models of new urbanization. From the perspective of the four major regions, the regional models of urbanization include a quality improvement model for urbanization in the eastern region, an in situ urbanization model in the central and western regions, and an urbanization and industrialization integrated development model in the northeast region. From the perspective of different zonal characteristics, these can be described respectively as an urbanization model of mountainous land under land resource constraints, an urbanization model of oases under water resource constraints, an urbanization model of traditional agricultural and reclamation areas, and an urbanization model of coastal zones. Given the complexity of the new urbanization problem, it is necessary to select some typical areas and carry out continuous and in-depth research with regard to specific scientific issues. Examples are research on the regional coordinated development of the multidimensional elements of new urbanization in Beijing-TianjinHebei and research on the development of urban agglomerations in Dawan District, which covers Guangdong, Hong Kong, and Macao.

\subsection{Urbanization and effects and mechanisms in the context of humans and social space}

Urbanization is also a humanistic and social process, and social space and its production are important elements of urbanization (Ye et al., 2011). The production of space has been one of the theoretical paradigms of urban research since the introduction of the concept in the 1970s. During the second half of the 20th century, the "spatial turn" in the humanities and social sciences (Lefebvre, 1991) involved a transformation from a focus on "production in space" to "production of space" (Ye, 2012). In the 21st century, the era of "space" has been entered. Spatial problems and social processes in the process of urbanization are co-existent and intertwined. Spatiality is as important as historicality and sociality. Urbanization and spatial production are intertwined (Harvey, 2000). Since the initiation of reform and opening up, China's rapid urbanization has been characterized by space production. This in turn is characterized by super-large land use and spatial expansion, ultra-fast development speed, super-government-led development, and high resource and environmental risks and reliance 
(Lin, 2007; Ye et al., 2017), as well as gentrification of rural areas and the development of social networks and the spatial differentiation of new urban immigrants in the context of rapid urbanization ( $\mathrm{Li}$ and $\mathrm{Liu}, 2011$; He et al., 2012). Therefore, a multi-scale theoretical and empirical analysis of urbanization is necessary to allow further discoveries and explanations of the social spatial effects and evolution mechanism of China's urbanization. In addition, the introduction in a critical manner of related theories of social, cultural, and institutional changes arising from Western urban studies, and innovations based on these, can also contribute to solving future urban social problems in China as well as to the future development of the subject on both academic and practical levels.

\subsection{Big data and the technical innovations in urbanization research}

In recent years, big data and its applications in general have become significant topics. Big data has already led to progress in the field of urban group spatial structure analysis and planning applications. International journals such as Nature and Science have published special issues on the topic of big data. If data torrents can be organized and used more effectively, this will allow greater opportunity to promote social development through science and technology. Although controversy remains about some aspects of big data, it is of great significance for the analysis and simulation of urban and regional development in human geography (Batty, 2013; Kwan, 2016). Based on theories of human and economic geography, it is possible to perform big data mining for urbanization. For example, multi-source big data on different scales can be used to analyze the characteristics of urbanization, urban systems, and residents' behavioral trajectories and social networks, thereby leading to breakthroughs in empirical modeling and the development of technical methods for the study of big data in new-type urbanization. In addition, regional spatial structure is an important part of human and economic geography, and also an important component of urbanization. Based on research into traditional point-line-plane spatial structure, high-precision simulations of the spatial structure trend-surface and its evolution can be performed, the spatial distribution and accessibility of the facilities and service levels of basic public services can be analyzed and evaluated, and theoretical and practical issues such as spatial justice can be explored.

\section{Conclusion and discussion}

China's new urbanization is in urgent need of both theoretical analysis and practical innovation. In the establishment of a theoretical basis, the specific needs imposed by China's national conditions must be taken into account. This not only creates a realistic basis for the scientific cognition of urbanization, but also provides a new way to cope with the theoretical tendency of Western centralism. The academic community has been exploring paths and models of theoretical innovation and is committed to changing Western centralism and making significant progress in the planning of urban systems with Chinese characteristics while taking account of the process of urbanization globally. China has entered the development stage of new urbanization. Such urbanization with Chinese characteristics has now accumulated rich practical experience. It is time to strengthen both independent theory and innovative methods from the standpoints of practical experience and theoretical background. Of course, the definitions of "West" and "China" have become increasingly blurred and 
complex, as a consequence of which urbanization research faces both challenges and unprecedented opportunities.

This paper has constructed a cognitive framework for the connotations of new urbanization theory. New urbanization with Chinese characteristics includes at least four aspects: humanism, harmonism, inclusiveness, and sustainability. It is becoming increasingly difficult to represent the essence of urbanization only by the urbanization rate among the population (Xue and Zeng, 2016). The core of new urbanization is the realization of its humanistic aspect. The macroscopic background change here lies in the transformation from structuralism to humanism. Structuralism in this context is concerned with the structural transformations of urban and rural populations, the evolution of the grand economic structure and social strata, and the structural changes in the rate of urbanization of the population. However, new urbanization emphasizes the basic public services available to people, coordination between people and land, community development, locality, daily life, and the rights of people in cities.

This requires a transformation of the traditional urbanization model with space production as the main line and with population and industrialization in leading to a new urbanization path with a high quality of human life, local culture, social justice, and civil rights at the core. This process may be long and full of contradictions, but it is undoubtedly the way for new urbanization to proceed in terms of value and concept. As pointed out in the Report of the 19th CPC National Congress (2017), "Socialism with Chinese characteristics has entered a new era, and the main contradictions in our society have been transformed into contradictions between the people's growing needs for a better life and the inadequate and imbalanced development." One aim of urbanization is to achieve the goal of a better life for people. To achieve this goal, interdisciplinary and cross-border theoretical and practical interactions are needed. Geography, especially human and economic geography, will play a vital role in the characterization and development of this discipline.

\section{References}

Ali I, Son H H, 2007. Defining and measuring inclusive growth: Application to the Philippines. ERD Working Paper Series.

Batty M, 2013. Big data, smart cities and city planning. Dialogues in Human Geography, 3(3): 274-279.

Cao G Z, Liu T, 2011. Rising role of inland regions in China's urbanization in the 21st century: The new trend and its explanation. Acta Geographica Sinica, 66(12): 1631-1643. (in Chinese)

Chai Y W, Zhang Y, Liu Z L, 2011. Spatial differences of home-work separation and the impacts of housing policy and urban sprawl: Evidence from household survey data in Beijing. Acta Geographica Sinica, 66(2): 157-166. (in Chinese)

Chen M X, Huang Y B, Tang Z P et al., 2014a. The provincial pattern of the relationship between urbanization and economic development in China. Journal of Geographical Sciences, 24(1): 33-45.

Chen M X, Liu W D, Tao X L, 2013a. Evolution and assessment on China's urbanization 1960-2010: Under-urbanization or over-urbanization? Habitat International, 38: 25-33.

Chen M X, Lu D D, Zhang H, 2009. Comprehensive evaluation and the driving factors of China's urbanization. Acta Geographica Sinica, 64(4): 387-398. (in Chinese)

Chen M X, Tang Z P, Bai Y P et al., 2015. Relational pattern of urbanization and economic development: Parameter re-evaluation of the Chenery model. Journal of Geographical Sciences, 25(8): 991-1002.

Chen M X, Zhang H, Liu W D et al., 2014b. The global pattern of urbanization and economic growth: Evidence from the last three decades. PloS ONE, 9(8): e103799.

Chen W, Song W X, Yang G S, 2013b. The situation, dynamic and trend of urbanization in the city concentrated area of Yangtze River Delta. Bulletin of the Chinese Academy of Sciences, 28(1): 28-38. (in Chinese) 
Chen Y G, 2012. On the urbanization curves: Types, stages, and research methods. Scientia Geographica Sinica, 32(1): 12-17. (in Chinese)

Cresswell T, 2013. Geographic Thought: A Critical Introduction. Wiley-Blackwell.

Fan J, Liu Y, Chen T et al., 2013a. The key strategies and innovative thinking for optimization on spatial pattern of urbanization in China. Bulletin of the Chinese Academy of Sciences, 28(1): 20-27. (in Chinese)

Fan J, Wang Q, Zhou K et al., 2013b. Preliminary research on spatial pattern of urbanization in mountainous areas of China. City Planning Review, 37(5): 9-15. (in Chinese)

Fang C L, 2014. Progress and the future direction of research into urban agglomeration in China. Acta Geographica Sinica, 69(8): 1130-1144. (in Chinese)

Fang C L, Wang D L, 2011. Comprehensive measures and improvement of Chinese urbanization development quality. Geographical Research, 30(11): 1931-1946. (in Chinese)

Field C B, Barros V R, Mach K J et al., 2014. Climate Change 2014: Impacts, Adaptation, and Vulnerability. Cambridge and New York: Cambridge University Press.

Friedmann J, 2006. Four theses in the study of China's urbanization. International Journal of Urban and Regional Research, 30(2): 440-451.

Fu B J, Leng S Y, Song C Q, 2015. The characteristics and tasks of geography in the New Era. Scientia Geographica Sinica, 35(8): 939-945. (in Chinese)

Gao X L, Ji Y, Fan J, 2014. An analytical tool for identifying the regional structure of urban system. Scientia Geographica Sinica, 34(1): 1-9. (in Chinese)

Gu C L, Guan W H, Liu H L, 2017. Chinese urbanization 2050: SD modeling and process simulation. Science China Earth Sciences, 47(7): 818-832. (in Chinese)

$\mathrm{Gu}$ C L, Wu L Y, 2008. Review of productions of the research of China's urbanization. Urban Problems, (12): 2-12. (in Chinese)

Harvey D, 2000. Space of Hope. Edinburgh: Edinburgh University Press.

He C F, Guo Q, Ma Y et al., 2014. Progress of economic geography in the West: A literature review. Acta Geographica Sinica, 69(8): 1207-1223. (in Chinese)

He J L, Huang X J, 2017. Quantitative analysis and challenges of Chinese human geography in the international academia since 2000. Progress in Geography, 36(1): 112-124. (in Chinese)

He S J, Qian J X, Xu Y X et al., 2012. Spatial-temporal evolution of rural gentrification amidst rapid urbanization: A case study of Xiaozhou Village, Guangzhou. Acta Geographica Sinica, 67(8): 1044-1056. (in Chinese)

IPCC, 2014. Mitigation of Climate Change, Working Group III Contribution to the IPCC Fifth Assessment Report.

Jin F J, 2013. Urbanization as a spatial means for human beings' development. Geographical Research, 32(9): 1761-1767. (in Chinese)

Kwan M P, 2016. Algorithmic geographies: Big data, algorithmic uncertainty, and the production of geographic knowledge. Annals of the American Association of Geographers, 106(2): 274-282.

Lefebvre H, 1991. The Production of Space. Oxford: Blackwell.

Li X J, Fan X S, Luo Q, 2014. The development of Chinese economic geography: A review on papers published in Acta Geographica Sinica from 1934 to 2013. Acta Geographica Sinica, 69(8): 1093-1108. (in Chinese)

Li X J, Luo Q, 2014. The coordinating ideas of new-form urbanization. China Population, Resources and Environment, 24(2): 47-53. (in Chinese)

Li Z G, Liu Y, 2011. Beyond spatial segregation: Neo-migrants and their social networks in Chinese cities. Acta Geographica Sinica, 66(6): 785-795. (in Chinese)

Lin G, 2007. Chinese urbanism in question: State, society, and the reproduction of urban spaces. Urban Geography, 28(1): 7-29.

Liu S H, Chen T, Cai J M, 2004. Peri-urbanization in China and its major research issues. Acta Geographica Sinica, 59(Suppl.): 101-108. (in Chinese)

Liu W D, 2014. Economic geography for spatial governance. Acta Geographica Sinica, 69(8): 1109-1116. (in Chinese)

Liu Y J, Li C G, 2009. Regulation model and mechanism of urbanization response to the industrial structure evolvement in northeast China. Acta Geographica Sinica, 64(2): 153-166. (in Chinese)

Liu Y S, Yang R, 2012. The spatial characteristics and formation mechanism of the county urbanization in China. Acta Geographica Sinica, 67(8): 1011-1020. (in Chinese)

Liu Y G, Jin J, 2014. Effect of city administrative division adjustment on urbanization: A case study of Zhongshan City. Progress in Geography, 33(8): 1047-1057. (in Chinese)

Liu Y G, Li Z G, Li B, 2014. A critical review of research methods of Western human geography: A combination of knowing and doing for Chinese human geography. Acta Geographica Sinica, 69(8): 1224-1233. (in Chinese)

Lu D D, 2013. The research framework of urbanization. Scientia Geographica Sinica, 33(8): 897-901. (in Chi- 
nese)

Lu D D, Cai Y L, 2001. Geography in China: As sciences of changing direction. Advance in Earth Sciences, 16(4): 467-472. (in Chinese)

Lu D D, Yao S M, 2007. A scientific thought about urbanization progress in China. Human Geography, 22(4): 1-5, 26. (in Chinese)

Lu D D, Yao S M, Li G P et al., 2007. Comprehensive analysis of the urbanization process based on China's conditions. Economic Geography, 27(6): 883-887. (in Chinese)

Luo X L, Tian D, Yang X Z, 2012. Rural transition of outflow village under the rapid urbanization: An empirical study on the middle Shanxi Province. Scientia Geographica Sinica, 32(10): 1209-1213. (in Chinese)

Miao C H, 1999. A retrospect and prospect on regional development theory. Progress in Geography, 18(4): 296-305. (in Chinese)

Ning Y M, 1998. New process of urbanization: Dynamics and features of urbanization in China since 1990. Acta Geographica Sinica, 53(5): 88-95. (in Chinese)

Porteous J D, 1976. Home: The territorial core. Geographical Review, 66(4): 383-390.

Soja E, 2009. The city and spatial justice. Spatial Justice, 1(1): 1-5.

Stocker T F, Qin D, Plattner G K et al., 2014. Climate Change 2013: The Physical Science Basis: Working Group I Contribution to the Fifth Assessment Report of the Intergovernmental Panel on Climate Change. Cambridge: Cambridge University Press.

Tuan Y, 1976. Humanistic geography. Annals of the Association of American Geographers, 66(2): 266-276.

Wei Y, Xiu C L, Sun P J, 2013. Dynamic mechanism of urbanization in China since 2000. Geographical Research, 32(9): 1679-1687. (in Chinese)

Wu C J, 1991. The core of geography research: Man-earth areal system. Economic Geography, (3): 7-12. (in Chinese)

Xue D S, Wang L, 2014. Progress of urban geography research in China since the 1980s. Acta Geographica Sinica, 69(8): 1117-1129. (in Chinese)

Xue D S, Zeng X J, 2016. Evaluation of China's urbanization quality and analysis of its spatial pattern transformation based on the modern life index. Acta Geographica Sinica, 71(2): 194-204. (in Chinese)

Xue D S, Zhen X, 2001. Research on rural urbanization in China: Origin, defination, progress and prospect. $H u$ man Geography, 16(5): 24-28. (in Chinese)

Yao S M, Lu D D, Wang C et al., 2011. Urbanization in China needs comprehensive scientific thinking: Exploration of the urbanization mode adapted to the special situation of China. Geographical Research, 30(11): 1947-1955. (in Chinese)

Ye C, 2012. The significant turns of thoughts on space in human geography. Human Geography, 27(5): 1-5. (in Chinese)

Ye C, Chai Y W, Zhang X L, 2011. Review on studies on production of urban space. Economic Geography, 31(3): 409-413. (in Chinese)

Ye C, Chen M X, Chen R S et al., 2014. Multi-scalar separations: Land use and production of space of Xianlin, a university town in Nanjing, China. Habitat International, 42: 264-272.

Ye C, Chen M X, Duan J J et al., 2017. Uneven development, urbanization and production of space in the middle-scale region based on the case of Jiangsu province, China. Habitat International, 66: 106-116.

Zhang P Y, 2004. Urban regeneration: Theory and practice in China's new urbanization. City Planning Review, (4): 25-30. (in Chinese)

Zhang X L, Du H R, 2013. New type of urbanization in arid zone of China: Regional characteristics and strategical choice of sustainable development path. Bulletin of the Chinese Academy of Sciences, 28(1): 46-53. (in Chinese)

Zhen F, Qin X, Xi G L, 2015. The innovation of geography and human geography in the information era. Scientia Geographica Sinica, 35(1): 11-18. (in Chinese)

Zhou C S, Ye C D, 2013a. Features and causes of urban spatial growth in Chinese metropolises. Acta Geographica Sinica, 68(6): 728-738. (in Chinese)

Zhou C S, Ye C D, 2013b. Progress on studies of urban spatial structure in China. Progress in Geography, 32(7): 1030-1038. (in Chinese)

Zhou S Y, Yang H Y, Kong X, 2011. The structuralistic and humanistic mechanism of placeness: A case study of 798 and M50 art districts. Geographical Research, 30(9): 1566-1576. (in Chinese)

Zhou Y X, 2006. Thoughts on the speed of China's urbanization. City Planning Review, (Suppl.): 32-35, 40. (in Chinese)

Zhu C, Jiang F Q, Wu L et al., 2017. On the problems of urbanization in the Yangtze River Delta under the background of global change. Acta Geographica Sinica, 72(4): 633-645. (in Chinese) 